\title{
Comparing hospital and patient demographics of adolescent versus adult patients undergoing primary total hip arthroplasty
}

Katelyn Pratt, Samantha Nguyen, Tony H Tzeng, Steven L Scaife, Sonia Vasdev, Mouhanad M El-Othmani, Khaled J Saleh *

School of Medicine, Southern Illinois University, United States

Received: July 18, 2015

Accepted: August 26, 2015

Online Published: September 3, 2015

DOI: $10.5430 /$ css.v2n1p11

URL: http://dx.doi.org/10.5430/css.v2n1p11

\begin{abstract}
Objective: Widening surgical indications and advances in technology have facilitated an increased number of total hip arthroplasty (THA) procedures among the adolescent population. The purpose of this study is to improve the understanding of inpatient and hospital demographics of adolescent THA patients as well as to compare these demographics with that of their more prevalent adult counterparts.

Methods: Data from the Kids' Inpatient Database and the Nationwide Inpatient Sample from 1997-2009 with a total of 1,652 adolescent and 603,968 adult THA patients were analyzed.

Results: Trends among the adolescent THA population included significant increases in procedures, total charges, and complication rates, while length of stay significantly decreased.

Conclusions: The comparison between adult and adolescent demographics found differences in diagnosis, ethnicity, insurance type, discharge status, and total charges.
\end{abstract}

Key Words: Total hip arthroplasty, Adolescent, Complication, Patient demographics, Nationwide inpatient sample

\section{INTRODUCTION}

Primary total hip arthroplasty (THA) in the adult population is well known in the medical field for its high functional outcomes and low complication rates. Although the majority of THA procedures are performed on adults 65 years and older, improvements in prosthetic design, fixation techniques, and bearing surfaces have resulted in an increased number of procedures among the adolescent population. ${ }^{[1-4]}$

The complexity of performing THA in adolescent patients is increased due to skeletal immaturity, poor bone quality associated with systemic disease or medications, and technical difficulties associated with previous surgeries. ${ }^{[5,6]}$ Adoles- cent patients have an increased likelihood of multiple revisions due to their life expectancy being longer than that of the hip implant. ${ }^{[7]}$ Additionally, the lifespan of the implant itself is shorter in adolescents as compared to adults. Factors contributing to accelerated implant failure in adolescent patients include higher post-operative activity level, history of multiple procedures, and presence of comorbid disease. ${ }^{[3,8]}$ Due to the difficulty of the procedure and the resultant need of multiple revision surgeries, it is important to carefully consider when it is appropriate to pursue THA in an adolescent patient.

While there have been many studies investigating differing

*Correspondence: Khaled J Saleh; Email: ksaleh@ siumed.edu; Address: School of Medicine, Southern Illinois University, United States. 
implants and surgical techniques in adolescent patients, there has been a lack of literature regarding the epidemiology of adolescent THA. Previous studies have shown that patient and hospital demographics affect outcomes in adult THA patients, yet despite the well-known differences between these patients and their adolescent counterparts, there is little information on adolescent THA demographics available. The purpose of this study is to (1) analyze year-to-year demographic trends occurring in the adolescent THA population, (2) to compare the demographics of adolescent THA patients to adult THA patients, and (3) to review how previous studies have demonstrated the effect of demographics on THA outcomes in adults.

\section{Methods}

Institutional review board exemption was obtained for this study from the Springfield Committee for Research Involving Human Subjects. Data was obtained from the Kids' Inpatient Database (KID) and the Nationwide Inpatient Sample (NIS). The NIS, which contains information on all inpatient stays, is released annually. The KID, which includes only patients 0 to 20 years of age, is released every three years and began in 1997. This study utilized data collected from adolescent patients 13-20 years of age (KID) and adults 65 years of age and older (NIS) from the years 1997, 2000, 2003, 2006, and 2009. This included information from 2,500 to 4,000 hospitals in 22 to 44 states.

Using International Classification of Disease-9 (ICD-9) code 81.51, information for all patients undergoing a primary THA was obtained for inclusion in this study. Variables which were analyzed included age, primary diagnosis, gender, ethnicity, primary payer, mean length of stay, total charges, hospital teaching status, and in-patient complications (see Table 1). Adolescent diagnoses were divided into avascular necrosis of the femur, osteoarthritis, juvenile rheumatoid arthritis, and other. Other included congenital deformity, juvenile osteochondrosis, traumatic arthropathy, adult-onset rheumatoid arthritis, and malignant neoplasm. Adult-onset rheumatoid arthritis is distinguished from juvenile rheumatoid arthritis by a diagnosis at age 16 or later. ${ }^{[9]}$ Adult diagnoses were separated into osteoarthritis, fracture, and other. Other diagnoses for adults included avascular necrosis, rheumatoid arthritis, and mechanical complication of internal orthopaedic device. A diagnosis of osteoarthritis for both adolescent and adult patients included generalized or localized and primary or secondary variants. Due to the small sample size, the ethnicity of adolescent patients was divided into Caucasian and non-Caucasian groups. Non-Caucasians included African Americans, Hispanics, Asian/Pacific Islanders, and Native Americans. Adult patients were divided into Caucasian, African American, Hispanic, and Other, which included Asian/Pacific Islanders and Native Americans.

Table 1. Independent variables

\begin{tabular}{|lll|}
\hline Age & Ethnicity: Adolescent & Hospital Status \\
13-20 (Adolescent) & Caucasian & Teaching \\
65 (Adult) & Non-Caucasian ${ }^{+}$ & Non-Teaching \\
Diagnosis: Adolescent & Ethnicity: Adult & Complications \\
Avascular Necrosis & Caucasian & General \\
Osteoarthritis & African American & Orthopaedic \\
Juvenile Rheumatoid & Hispanic & \\
Arthritis & Other ${ }^{++}$ & Mean Length of \\
Other & & Stay \\
Diagnosis: Adult & Primary Payer & Charges \\
Osteoarthritis & Medicare & \\
Fracture & Medicaid & \\
Other & Private & \\
Gender & Disposition & \\
Male & Routine & \\
Female & Transfer to another & \\
& facility & \\
& Home health care & \\
\hline
\end{tabular}

* Includes congenital deformity, juvenile osteochondosis, traumatic arthropathy, adult-onset rheumatoid arthritis, and malignant neoplasm; ${ }^{* * *}$ Includes avascular necrosis, rheumatoid arthritis, and mechanical complication of internal orthopedic device; ${ }^{+}$Includes African American, Hispanic, Asian/Pacific Islander, and Native American; ${ }^{++}$Includes Asian/Pacific Islander and Native American

The data were analyzed using SAS (North Carolina, USA) 9.2 with the FREQ procedure, which produces frequency and cross tabulation tables and computes statistics for contingency. The output from this procedure was the source of the $p$-value and trend statistics presented in this paper. $P$-values less than .05 were considered significant. Results were weighted in order to facilitate accurate comparison of statistics across the different time points.

\section{RESUlts}

A total of 1,652 adolescent and 603,968 adult patients who underwent THA were analyzed. There were nearly 3 times as many adolescent procedures in 2009 as compared to 1997 (see Figure 1). Most adolescent patients were diagnosed with avascular necrosis $(45 \%)$, while most adult patients were diagnosed with osteoarthritis (88\%) (see Figure 2). Across all years of data, $64 \%$ of adult patients and $59 \%$ of adolescent patients were female. The percentage of male adolescent patients increased from 24\% in 1997 to $45 \%$ in 2009. Caucasian patients comprised $63 \%$ of adolescents who underwent THA, with no significant difference between Caucasians and nonCaucasians. There was a significant difference between both Caucasian and African American patients and Caucasian and Hispanic patients in the adult population. In 2009, 
$91 \%$ of adult patients undergoing THA were Caucasian (see Figure 3). Significantly more adolescent patients used private insurance than all other insurance types combined. From 1997 to 2009, there was a significant decrease in use of private insurance and an increase in other primary payers, with the shift being primarily towards Medicaid (see Figure 4). Significantly more adult patients reported Medicare as their primary payer (see Figure 5).

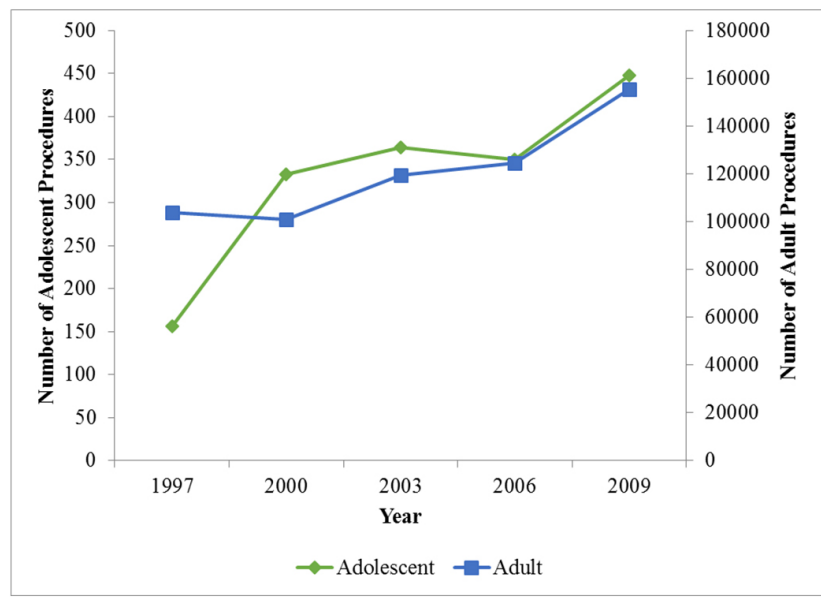

Figure 1. Number of THA procedures per year

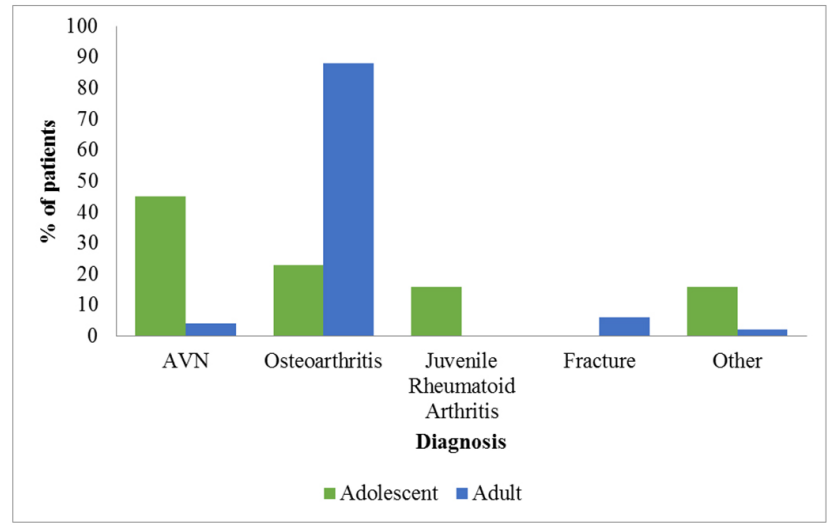

Figure 2. Primary diagnosis by percentage (all years)

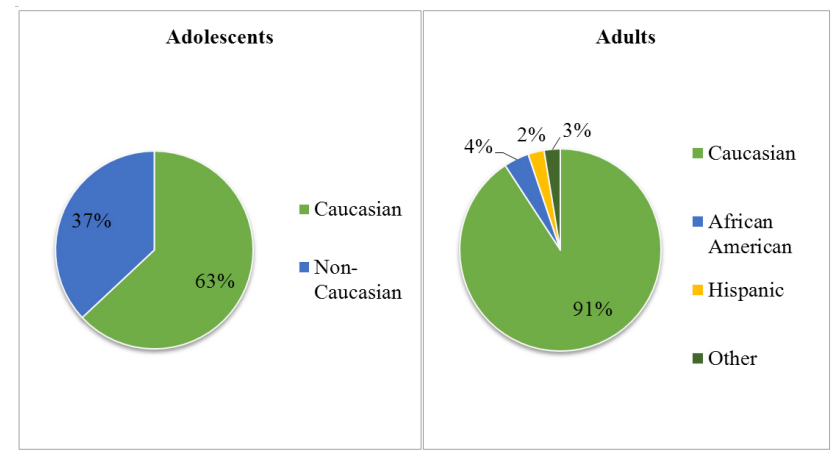

Figure 3. Ethnicity (all years)

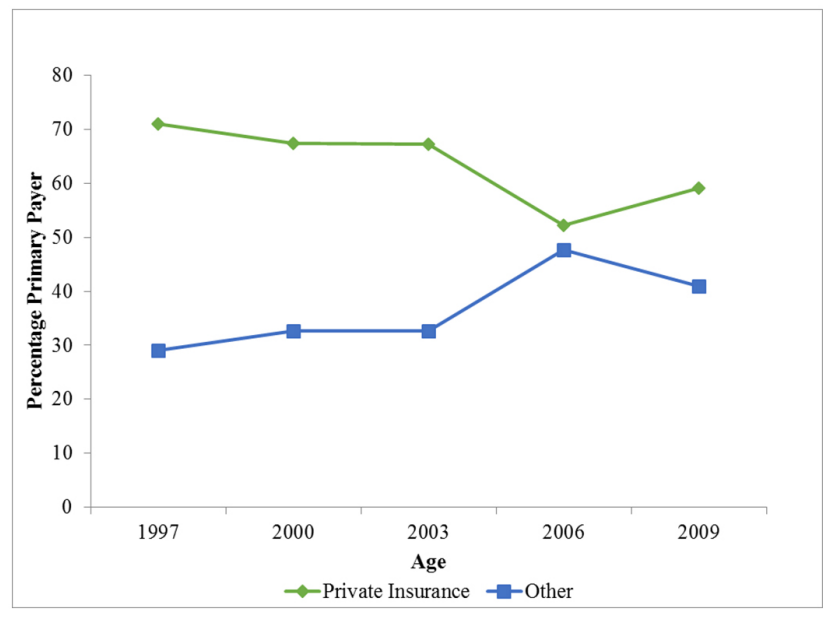

Figure 4. Adolescent primary payer by year

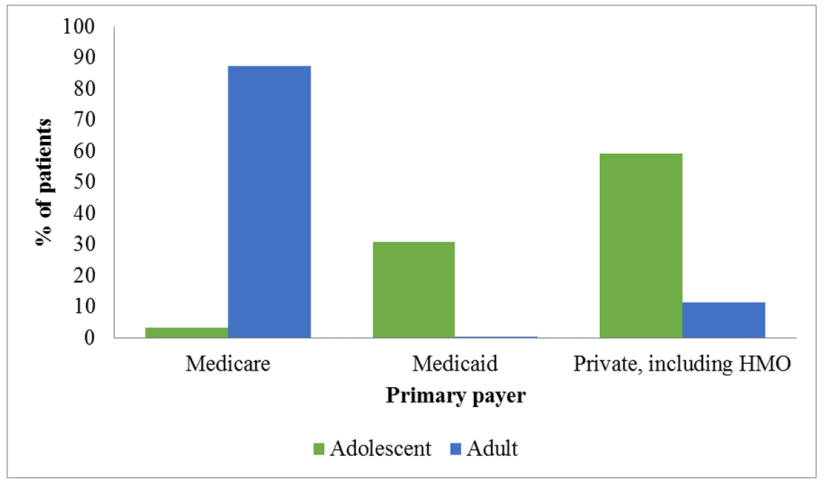

Figure 5. Primary payer (2009 only)

The majority of adolescent patients were discharged routinely in 1997, 2000, and 2003. Patients discharged to their home with self-care only were considered routine. In 2006 and 2009, the majority of adolescent patients were transferred to another facility or home health care (see Figure 6). The difference between adolescent and adult patients undergoing routine discharge was significant. In $2009,45 \%$ of adolescent patients were discharged routinely, $43 \%$ were discharged to home health care, and $11 \%$ were transferred to another facility. In adults, $15 \%$ of patients were discharged routinely, $32 \%$ were discharged to home health care, and $52 \%$ were transferred to another facility (see Figure 7). A significant decrease in length of stay was observed for adolescent patients from 7.23 days in 2000 to 4.09 days in 2009. The length of stay for adult patients decreased from 5.09 days in 1997 to 3.75 days in 2009. In 2009, there was no significant difference in length of stay between adolescent and adult patients. There were significant increases in total charges for adolescent patients from 1997 to 2003, 2003 to 2006, and 2006 to 2009 (see Figure 8). In 2009, mean total charges were $\$ 65,154$ for adolescent patients compared to $\$ 48,608$ for adults. 


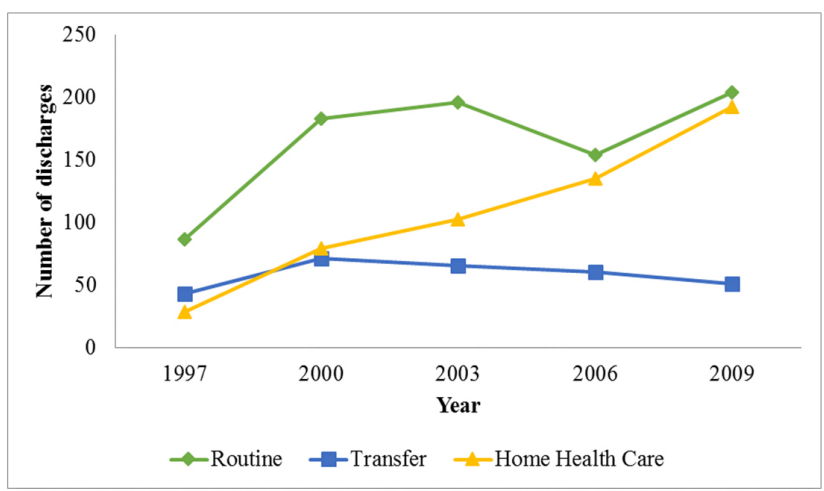

Figure 6. Adolescent disposition

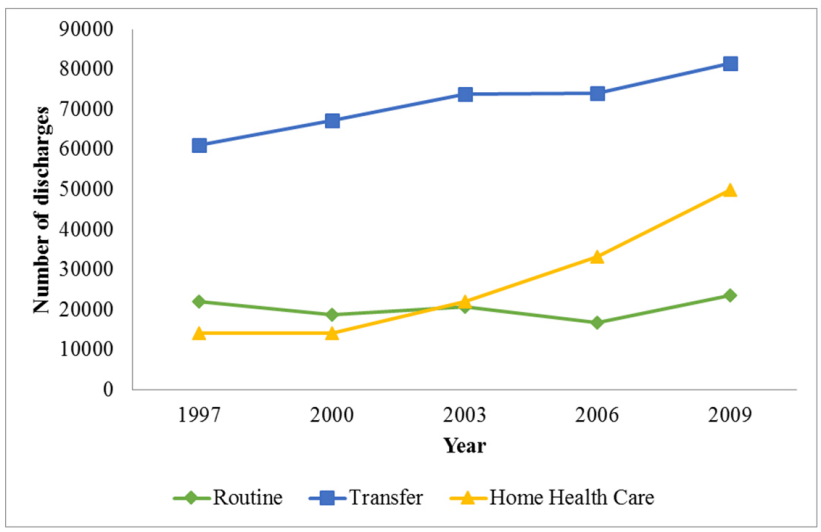

Figure 7. Adult disposition

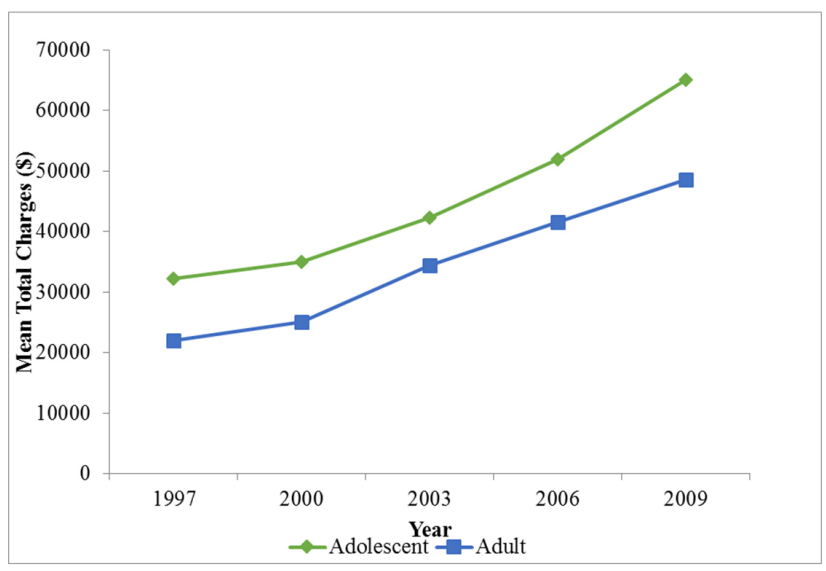

Figure 8. Mean total charges

Significantly more adolescent THA procedures were performed in teaching hospitals versus non-teaching hospitals, with the percentage of adolescent procedures performed in teaching hospitals increasing from $57 \%$ in 1997 to $81 \%$ in 2009 . Overall, $60 \%$ of adult procedures were performed in a non-teaching hospital (see Figure 9). The overall complication rate was $8 \%$ in the KID and $6 \%$ in the NIS. The adolescent population had a significant increase in complication rates from 1997 to 2009 (see Figure 10). There was no significant trend across years in the percentage of complications in the adult population. There was no significant relationship between complication rate and hospital teaching status.

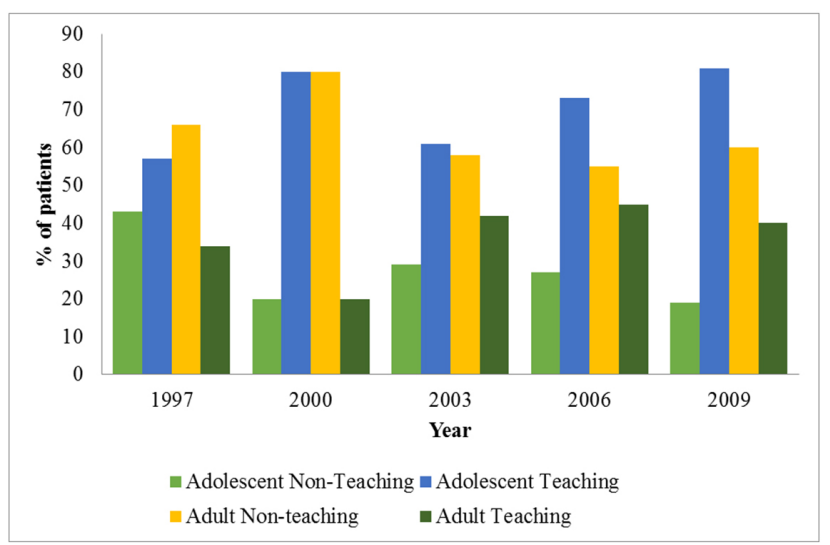

Figure 9. Hospital teaching status (percentage)

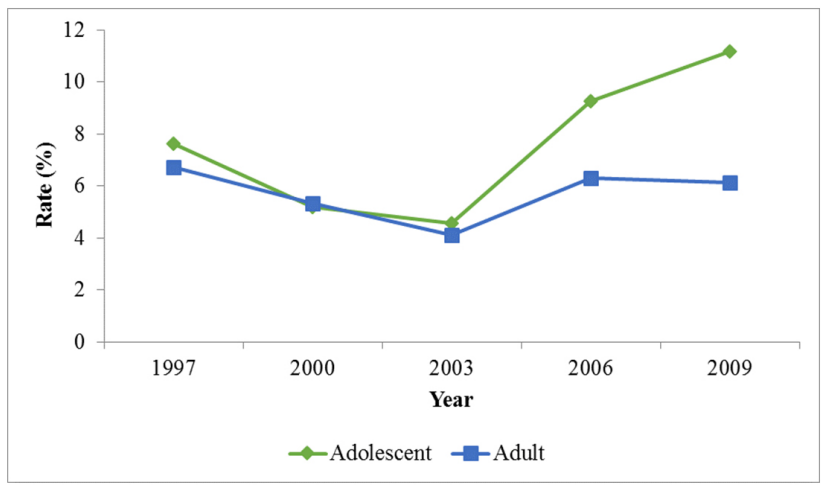

Figure 10. Complication rate

\section{Discussion}

The most prevalent primary diagnosis in adolescent patients was avascular necrosis of the femur (AVN) $(45 \%)$, corresponding with previous findings by Clohisy et al. (44\%) and Patel et al. (69\%). ${ }^{[4,10]}$ Avascular necrosis can have both traumatic and atraumatic origins. Traumatic cases are induced by fractures to the proximal femur. ${ }^{[11]}$ The majority of atraumatic cases are steroid-induced or chemotherapyinduced. ${ }^{[12,13]}$ Other diagnoses leading to THA in adolescent patients include osteoarthritis, juvenile rheumatoid arthritis, congenital deformity of the hip, juvenile osteochondrosis, rheumatoid arthritis, and malignant neoplasm. ${ }^{[4,5,10,14-18]}$

In contrast, $88 \%$ of the adult population had a diagnosis of osteoarthritis due to structural damage to articular cartilage and the chondrolabral complex. ${ }^{[19]}$ Elderly patients were less likely than adolescents to have an underlying systemic disease which contributed to their need for THA. Patients undergoing THA secondary to a systemic disease typically 
report worse results than those with isolated unilateral or bilateral disease, which could indicate that the adult population is more suited for THA than the adolescent population in most cases. ${ }^{[10]}$

Both the KID and the NIS revealed that more females than males undergo THA each year, with females making up $64 \%$ of the adult population and $59 \%$ of the adolescent population in 2009. Some studies have confirmed these findings, showing that $60 \%$ of THA patients are females while other studies found that there is no significant association between gender and the incidence of THA. ${ }^{[20-24]}$ Previous studies in adults have shown that women have poorer function following THA, less improvement relative to baseline, less postoperative pain, and lower in-hospital mortality. ${ }^{[8,25]}$ This indicates that the risks and benefits of THA in adolescent patients may differ between males and females. Though the patients in the KID showed no significant differences in procedure rates between Caucasians, African Americans, and Hispanics, there was a statistically significant difference in utilization rates between these ethnic groups in the adult population. This confirms previous findings in the adult population which stated that African Americans and Hispanics undergo total joint arthroplasty procedures at a lower frequency than Caucasians. ${ }^{[26,27]}$

In adults, differences in use rates among African Americans and Hispanics are likely to be related to treatment preferences. ${ }^{[2]}$ The primary diagnosis associated with THA may explain the differences in adolescent and adult populations in use rates among ethnicities. Although non-Caucasian adolescents and their parents may also be hesitant to undergo THA, the incidence of certain co-morbidities which are risk factors for avascular necrosis is increased in the non-Caucasian population, contributing to an increased percentage of THA procedures needed in non-Caucasian adolescents. ${ }^{[13]}$ Studies in adults have shown better outcomes in Caucasian patients, which may be related to differences in preoperative expectations. ${ }^{[26]}$ It is important to consider that this may indicate a difference in outcomes among different ethnicities in the adolescent population as well. Data from the KID showed a significant trending away from private insurance and towards Medicaid. In contrast, the majority of patients in the NIS use Medicare as their primary payer. It previously has been shown that those covered by HMOs or something other than HMOs or Medicare experienced significantly higher complication rates. ${ }^{[29]}$ This study found an increase in the use of Medicaid among adolescent patients with a concurrent rise in complication rate. While a causal relationship cannot be determined, one must consider that Medicaid patients may experience worse outcomes when deciding to pursue THA.

In both the adolescent and adult populations, there has been a significant decrease of routine discharge and an increase in transfer to another facility or discharge to home health care, which is similar to results found be Liu et al. ${ }^{[20]}$ At the same time, there has been a significant decrease in the length of stay and a significant increase in total charges, with the increase in total charges being significantly higher for adolescent patients than adult patients. Other studies have confirmed that there has been a decrease in length of stay over the years, but despite length of stay being a major determinant of medical costs, the cost of THA continues to rise. ${ }^{[20,25,30-32]}$

Over the last decade, prices of implants have increased by $212 \%$ in the United States. Implant costs make up the largest expense associated with THA and can range from $\$ 7,152$ to $\$ 23,051 .{ }^{[33,34]}$ Increased age and Medicare as primary payer were both associated with higher device costs, so this is unlikely to account for the cost differential between adolescent and adult patients. ${ }^{[33]}$ Charges increased by a factor of 1.62 from 1997 to 2004 while the inflation factor was only 1.18. ${ }^{[35]}$ Factors that have been associated with increased charges include being less than 65 years of age, increased disease severity, increased length of stay, and diagnosis other than osteoarthritis, rheumatoid arthritis, or avascular necrosis. ${ }^{[31]}$ In adult patients, $92 \%$ of patients had one of these three diagnoses, compared to $68 \%$ of adolescents. This could be one contributing factor to increased mean charges in adolescents. In addition to increased cost per procedure for adolescents compared to adults, limited implant longevity leads to multiple revisions in adolescent patients. ${ }^{[4]}$ Multiple revisions coupled with continually rising costs per procedure could result in an extensive financial strain for both the patient and the healthcare system.

While the majority of adolescent THAs were performed in teaching hospitals, the opposite was true for adult THAs. Adolescent THA procedures are typically more difficult than adult THA procedures. Because of the complexity of the procedure, THA in adolescent patients is more likely to be performed in large, urban hospitals, which are often teaching hospitals. ${ }^{[5,6]}$ Given the wide use of THA in the adult population for many years, smaller, non-teaching hospitals are often still equipped with the personnel and resources to handle non-complicated cases. Woolson et al. found that the average post-operative hip clinical scores were not significantly different between patients operated on in a teaching hospital versus private practice. ${ }^{[36]}$ Liu et al. found that performance in a teaching hospital decreases mortality, complications, and LOS following THA. ${ }^{[20]}$ In contrast, this study found no significant relationship between complication rate and hospital teaching status. This disparity could be due to the use of another nationwide database which included a different 
selection and number of hospitals.

Complication rates were found to be $8 \%$ in adolescent patients and $6 \%$ in adult patients, corresponding to other studies. ${ }^{[4,10,29]}$ Girard et al. found that complication rates were higher in patients younger than 30 years of age. ${ }^{[37]}$ Higher complication rates in adolescent patients were thought to be due to retained instrumentation from previous surgeries, extensive scar tissue, poor bone quality, abductor muscle insufficiency, and contractures. ${ }^{[2]}$ A study by Thompson et $a l$. found that older patients were more likely to experience general complications; however, this study found that the percentage of general complications in the adolescent population was $4 \%$ compared to $3 \%$ in the adult population. ${ }^{[29]}$ In addition, the percentage of orthopaedic complications was $4 \%$ in the adolescent population compared to $2 \%$ in adults In general, patients with worse preoperative health experience increased complication rates. ${ }^{[38]}$ Overall, the adolescent complication rate increased from 1997 to 2009, despite presumed advances in the standard of care. This increase in complication rate is possibly due to improved reporting of complications. It is also possible that more difficult cases were performed in later years, leading to the increased complication rate. Further investigation is required to delineate the causative reasons for this trend.

Despite the efficacy of primary THA, revision surgery remains clinically and economically burdensome, accounting for nearly $25 \%$ of arthroplasties performed in adult patients in the United States. ${ }^{[39]}$ In comparison to the adult population, adolescent patients experience lower implant survival rates. Torchia et al. found that the probability of failure after 15 years was $45 \%$ in adolescents compared to $13 \%$ in adults, indicating that revision surgery accounts for an even greater percentage of THA procedures in the adolescent population. ${ }^{[14]}$ Not only is revision THA financially demanding, but it also has less favorable outcomes than primary surgery. ${ }^{[40]}$ Studies in adult THA patients have shown that certain patient and hospital demographics can positively or negatively affect the outcome of THA. However, most studies on adolescent THA have focused solely on implant survival, bearing types, and surgical technique. An understanding of adolescent patient and hospital demographics and how they affect outcomes may help the clinician and patient decide when it is most appropriate to pursue THA. Pursuing THA at an optimal time could lead to improved quality of life for the patient and decreased economic burden for the healthcare system.

While the KID and NIS provide useful information regarding inpatient hospital stays, this study is limited based on what is available in the database. Certain information was unable to be obtained, including underlying diagnoses leading to AVN, length of time to complications, and any information obtained following the inpatient stay. Due to the nature of the database, it is not possible to analyze data on satisfaction or surgical outcomes beyond the primary hospital stay. In addition, there is a very limited number of adolescent patients with conditions that result in the need for THA or other related treatment modalities. While it would be beneficial to compare demographics of adolescent THA to those undergoing alternative treatments, this data is unable to be analyzed at this time due to the small sample size. In the future, as adolescent THA becomes more prevalent, such a comparison could be informative and helpful for clinicians to decide if THA or an alternative option is the best treatment plan.

Overall, there were significant differences between adolescent and adult patients in primary diagnosis, total charges, complication rates, and hospital teaching status. Gender trends were similar between the two groups, but ethnic differences were not. Previous studies in adult populations have shown that patient and hospital demographics impact surgical outcomes. While only a small percentage of adolescents undergo THA each year, the number is on the rise, necessitating further studies to investigate how these demographics may affect outcomes in this patient population.

\section{REFERENCES}

[1] Jäger M, Begg MJ, Ready J, et al. Primary total hip replacement in childhood, adolescence and young patients: Quality and outcome of clinical studies. Technol Health Care. 2008; 16(3): 195-214. PMid: 18641439.

[2] Polkowski GG, Callaghan JJ, Mont MA, et al. Total hip arthroplasty in the very young patient. The Journal of the American Academy of Orthopaedic Surgeons. 2012; 20(8): 487-97. PMid: 22855851. http://dx.doi.org/10.5435/JAAOS-20-08-487

[3] Kamath AF, Sheth NP, Hosalkar HH, et al. Modern total hip arthroplasty in patients younger than 21 years. The Journal of arthroplasty.

2012; 27(3): 402-8. PMid: 21723701. http://dx.doi.org/10. $1016 / j$.arth. 2011.04.042

[4] Patel NK, Luff T, Whittingham-Jones P, et al. Total hip arthroplasty in teenagers: an alternative to hip arthrodesis. Hip Int. 2012; 22(6): 621-7. PMid: 23233183. http://dx.doi.org/10.5301/HIP.2 012.10352

[5] Jager M, Begg MJ, Ready J, et al. Primary total hip replacement in childhood, adolescence and young patients: quality and outcome of clinical studies. Technology and health care: official journal of the European Society for Engineering and Medicine. 2008; 16(3): 195-214. 
[6] Bessette BJ, Fassier F, Tanzer M, et al. Total hip arthroplasty in patients younger than 21 years: a minimum 10-year follow-up. Canadian Journal of Surgery. 2003; 46(4): 257-62. PMid: 12930101.

[7] Schmitz MW, Busch VJ, Gardeniers JW, et al. Long-term results of cemented total hip arthroplasty in patients younger than 30 years and the outcome of subsequent revisions. BMC Musculoskeletal Disorders. 2013; 14: 37. PMid: 23339294. http://dx.doi .org/10.11 86/1471-2474-14-37

[8] Santaguida PL, Hawker GA, Hudak PL, et al. Patient characteristics affecting the prognosis of total hip and knee joint arthroplasty: a systematic review. Can J Surg. 2008; 51(6): 428-36. PMid: 19057730.

[9] Jolles BM, Bogoch ER. Juvenile arthritis patients report favorable subjective outcomes of hip arthroplasty despite poor standard outcome scores. The Journal of arthroplasty. 2012; 27(9): 1622-8. PMid: 22522107. http://dx.doi.org/10.1016/j.arth. 2012 .02 .024

[10] Clohisy JC, Oryhon JM, Seyler TM, et al. Function and fixation of total hip arthroplasty in patients 25 years of age or younger. Clin Orthop Relat Res. 2010; 468(12): 3207-13. PMid: 20668972. http://dx.doi.org/10.1007/s11999-010-1468-4

[11] Bartonicek J, Vávra J, Bartoška R, et al. Operative treatment of avascular necrosis of the femoral head after proximal femur fractures in adolescents. International orthopaedics. 2012; 36(1): 14957. PMid: 21796335 . http://dx.doi .org/10.1007/s00264-0 11-1272-0

[12] Caramaschi P, Biasi D, Dal Forno I, et al. Osteonecrosis in Systemic Lupus Erythematosus: An Early, Frequent, and Not Always Symptomatic Complication. Autoimmune Diseases. 2012; 2012: 725249. PMid: 22919470. http://dx.doi.org/10.1155/2012/725249

[13] Mahadeo KM, Oyeku S, Taragin B, et al. Increased prevalence of osteonecrosis of the femoral head in children and adolescents with sickle-cell disease. American journal of hematology. 2011; 86(9): 806-8. PMid: 21850660. http://dx.doi.org/10.1002/ajh.2 2103

[14] Torchia ME, Klassen RA, Bianco AJ. Total hip arthroplasty with cement in patients less than twenty years old. Long-term results. The Journal of bone and joint surgery American volume. 1996; 78(7): 995-1003. PMid: 8698735.

[15] Bsila RS, Inglis AE, Ranawat CS. Joint replacement surgery in patients under thirty. The Journal of bone and joint surgery American volume. 1976; 58(8): 1098-104. PMid: 1002751.

[16] Girard J, Glorion C, Bonnomet F, et al. Risk factors for revision of hip arthroplasties in patients younger than 30 years. Clinical orthopaedics and related research. 2011; 469(4): 1141-7. PMid: 21086195. http://dx.doi.org/10.1007/s11999-010-1669-x

[17] Klassen RA, Parlasca RJ, Bianco AJ Jr. Total joint arthroplasty. Applications in children and adolescents. Mayo Clinic proceedings Mayo Clinic. 1979; 54(9): 579-82.

[18] Restrepo C, Lettich T, Roberts N, et al. Uncemented total hip arthroplasty in patients less than twenty-years. Acta orthopaedica Belgica. 2008; 74(5): 615-22. PMid: 19058694.

[19] Schoenecker PL, Clohisy JC, Millis MB, et al. Surgical management of the problematic hip in adolescent and young adult patients. The Journal of the American Academy of Orthopaedic Surgeons. 2011; 19(5): 275-86. PMid: 21536627.

[20] Liu SS, Della Valle AG, Besculides MC, et al. Trends in mortality, complications, and demographics for primary hip arthroplasty in the United States. Int Orthop. 2009; 33(3): 643-51. PMid: 18461326. http://dx.doi.org/10.1007/s00264-008-0549-4

[21] Lavernia CJ, Alcerro JC, Contreras JS, et al. Patient Perceived Outcomes After Primary Hip Arthroplasty: Does Gender Matter? Clinical Orthopaedics \& Related Research. 2011; 469(2): 348-54.
PMid: 20700673. http://dx.doi.org/10.1007/s11999-010 $-1503-5$

[22] Kurtz S, Mowat F, Ong K, et al. Prevalence of Primary and Revision Total Hip and Knee Arthroplasty in the United States from 1990 through 2002. Journal of Bone \& Joint Surgery American Volume. 2005; 87(7): 1487-97. PMid: 15995115. http://dx.doi .org/10. 2106/JBJS.D. 02441

[23] Singh JA. Epidemiology of knee and hip arthroplasty: a systematic review. Open Orthop J. 2011; 5: 80-5. PMid: 21584277. http://dx.doi.org/10.2174/1874325001105010080

[24] Hausmann LR, Mor M, Hanusa BH, et al. The Effect of Patient Race on Total Joint Replacement Recommendations and Utilization in the Orthopedic Setting. JGIM: Journal of General Internal Medicine. 2010; 25(9): 982-8. PMid: 20509053. http://dx.doi.org/10 1007/s11606-010-1399-5

[25] Jimenez-Garcia R, Villanueva-Martınez M, Fernandez-de-Las-Penas C, et al. Trends in primary total hip arthroplasty in Spain from 2001 to 2008: Evaluating changes in demographics, comorbidity, incidence rates, length of stay, costs and mortality. BMC Musculoskeletal Disorders. 2011; 12: 43. PMid: 21306615. http: $/ / \mathrm{dx}$.doi.org/10.1186/1471-2474-12-43

[26] Lavernia CJ, Lee D, Sierra RJ, et al. Race, ethnicity, insurance coverage, and preoperative status of hip and knee surgical patients. The Journal of arthroplasty. 2004; 19(8): 978-85. PMid: 15586333. http://dx.doi.org/10.1016/j.arth.2004.03.028

[27] Lavernia CJ, Alcerro JC, Contreras JS, et al. Ethnic and Racial Factors Influencing Well-being, Perceived Pain, and Physical Function After Primary Total Joint Arthroplasty. Clinical Orthopaedics and Related Research. 2011; 469(7): 1838-1845. PMid: 21409460. http://dx.doi.org/10.1007/s11999-011-1841-y

[28] Ginsberg P. Can hospitals and physicians shift the effects of cuts in Medicare reimbursement to private payers? Health Aff (Millwood) 2003; Suppl Web Exclusives: 472-9. http://dx.doi.org/10.13 $77 /$ hlthaff.w3.472

[29] Thompson R, Kane RL, Gromala T, et al. Complications and shortterm outcomes associated with total hip arthroplasty in teaching and community hospitals. The Journal of arthroplasty. 2002; 17(1): 32-40. PMid: 11805922. http://dx.doi.org/10.1054/arth.2002.2 8725

[30] Abbas K, Umer M, Qadir I, et al. Predictors of length of hospital stay after total hip replacement. Journal of orthopaedic surgery (Hong Kong). 2011; 19(3): 284-7.

[31] Tien WC, Kao HY, Tu YK, et al. A population-based study of prevalence and hospital charges in total hip and knee replacement. International orthopaedics. 2009; 33(4): 949-54. PMid: 18612638. http://dx.doi.org/10.1007/s00264-008-0612-1

[32] Husted H, Jensen CM, Solgaard S, et al. Reduced length of stay following hip and knee arthroplasty in Denmark 2000-2009: from research to implementation. Archives of orthopaedic and trauma surgery. 2012; 132(1): 101-4. PMid: 21947286. http://dx.doi.o $\mathrm{rg} / 10.1007 / \mathrm{s} 00402-011-1396-0$

[33] Robinson JC, Pozen A, Tseng S, et al. Variability in Costs Associated with Total Hip and Knee Replacement Implants. Journal of Bone \& Joint Surgery, American Volume. 2012; 94(18): 1693-8. PMid: 22878562. http://dx.doi.org/10.2106/JBJS.K. 00355

[34] Antoniou J, Martineau PA, Filion KB, et al. In-hospital cost of total hip arthroplasty in Canada and the United States. J Bone Joint Surg Am. 2004; 86-A(11): 2435-9. PMid: 15523015.

[35] Kim S. Changes in Surgical Loads and Economic Burden of Hip and Knee Replacements in the US: 1997-2004. Arthritis \& Rheumatism. 2008; 59(4): 481-8. PMid: 18383407. http://dx.doi.org/10. 1002/art. 23525 
[36] Woolson ST, Kang MN. A comparison of the results of total hip and knee arthroplasty performed on a teaching service or a private practice service. J Bone Joint Surg Am. 2007; 89(3): 601-7. PMid: 17332109. http://dx.doi.org/10.2106/JBJS.F.00584

[37] Girard J, Bocquet D, Autissier G, et al. Metal-on-metal hip arthroplasty in patients thirty years of age or younger. J Bone Joint Surg Am. 2010; 92(14): 2419-26. PMid: 20962192. http://dx.doi.o $\mathrm{rg} / 10.2106 / J B J S . I .01644$

[38] Hooper GJ, Rothwell AG, Hooper NM. The Relationship Between the American Society of Anesthesiologists Physical Rating and Outcome Following Total Hip and Knee Arthroplasty. Journal of Bone
\& Joint Surgery, American Volume. 2012; 94(12): 1065-70. PMid: 22717825. http://dx.doi.org/10.2106/JBJS. J . 01681

[39] Chang RW, Pellisier JM, Hazen GB. A cost-effectiveness analysis of total hip arthroplasty for osteoarthritis of the hip. JAMA : the journal of the American Medical Association. 1996; 275(11): 85865. PMid: 8596224. http://dx.doi.org/10.1001/jama.1996 .03530350040032

[40] Ulrich SD, Seyler TM, Bennett D, et al. Total hip arthroplasties: what are the reasons for revision? International orthopaedics. 2008; 32(5): 597-604. PMid: 17443324. http://dx.doi.org/10.1007/s00 264-007-0364-3 